\title{
Tumor Misdiagnosed as Cancer of the Sphenoid Sinus: Case Report and Literature Review ${ }^{*}$
}

\author{
El Fatemi Hinde ${ }^{1}$, Bennani Amal ${ }^{1}$, Souaf Ihsane ${ }^{1}$, Zaki Zouhir ${ }^{2}$, Alami Noureddine ${ }^{2}$, Amarti Afaf ${ }^{1}$ \\ ${ }^{1}$ Department of Pathology, Hassan II Teaching Hospital, Fez, Morocco \\ ${ }^{2}$ Department of Oto-Rhino-Laryngology, Hassan II Teaching Hospital, Fez, Morocco \\ Email: hinde0012@hotmail.com
}

Received June 12, 2012; revised July 23, 2012; accepted August 12, 2012

\begin{abstract}
Respiratory epithelial adenomatoid hamartoma (REAH) is an uncommon lesion of the upper aerodigestive tract first described by Wenig and Heffner in 1995 as prominent glandular proliferations lined by ciliated respiratory epithelium originating from the surface epithelium. Case Report: We report a case of 48-year-old women with nasal polyposis history, which consults for nasal obstruction, with suspicion of malignancy on CT. Surgical resection showed a respiratory epithelial adenomatoid hamartoma (REAH) of the nasal cavity. Conclusion: REAH is a recently described pathologic entity that can present rhinorrhea, epistaxis, hyposmia, and headaches. It is a rare lesion of nasal and paranasal sinuses, but should be considered in the differential diagnosis because it is a benign lesion and complete surgical resection is curative.
\end{abstract}

Keywords: Nasal Cavity; REAH; Nasal Polyposis; Hamartoma; Nasal Obstruction

\section{Introduction}

The respiratory epithelial adenomatoid hamartoma (REAH) was first described as a distinct lesion by Wenig and Heffner [1] in 1995. They identified 31 cases from the files of the Otolaryngic Tumor Registry at the Armed Forces Institute of Pathology. These lesions occurred in the nasal cavity, paranasal sinuses, and nasopharynx and demonstrated distinctive clinical and histopathologic features that permitted separation as a discrete pathologic process. We report a case of respiratory epithelial adenomatoid hamartoma of the left sphenoid sinus mimicking malignancy in CT. Awareness of this lesion is important because inverted schneiderian papilloma and adenocarcinoma may be included in the histopathological differential diagnosis. Conservative surgical removal is curative and recurrence has not been reported.

\section{Case Report}

We report a case of 48-year-old women with nasal polyposis history, which consults for nasal obstruction. His symptoms have worsened over a 10-month period despite oral steroid and antibiotic medications. The CT of nasal cavity and sinus showed soft tissue density (Figure 1) filling of the nasal cavity, choanae, maxillary sinus, the left frontal sinus, ethmoidal cells bilaterally and through

\footnotetext{
"The authors declare no conflict of interest.
}

the sphenoid sinus. Obstruction of the ostia of the maxillary sinuses. Thinning of the walls of the maxillary sinuses and ethmoidal partitions the cavum and mastoid air cells are normal. The mass was excised completely under local anaesthesia. Gross examination of the specimen showed a $1.5 \mathrm{~cm}$ pale coloured fleshy rounded firm mass with smooth surface. There were no areas of haemorrhage or altered texture on the cut section. Histopathological examination by routine haematoxyline and eosin stained sections showed a well encapsulated mass with compressed parenchyma. It comprised of lobular adenomatous proliferations with tubular glands showing ciliated columnar epithelium at places. Some of the glands showed large amounts of secretions. Goblet cells were seen dispersed among the lining epithelium of glands. The stroma showed hyalinization and a focal chronic inflammatory infiltrate. No atypia or increased mitotic figures were observed (Figure 2). The lesion was diagnosed as respiratory epithelial adenomatoid hamartoma (REAH).

\section{Discussion}

The REAH is a rare lesion limited in its site of occurrence to the nasal cavity, paranasal sinuses, and nasopharynx [1-4]. Its rarity is evidenced by the extremely limited number of journal article references found in a search of the National Library of Medicine database, $[1,5,6]$ with 2 


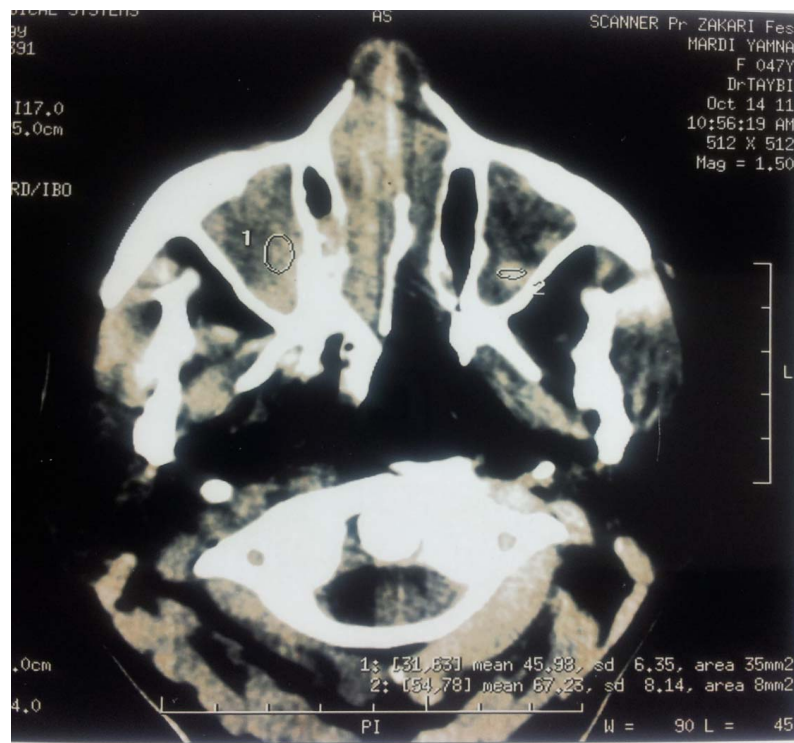

Figure 1. The CT of nasal cavity and sinus showed soft tissue density filling of the nasal cavity, choanae, maxillary sinus, the left frontal sinus.

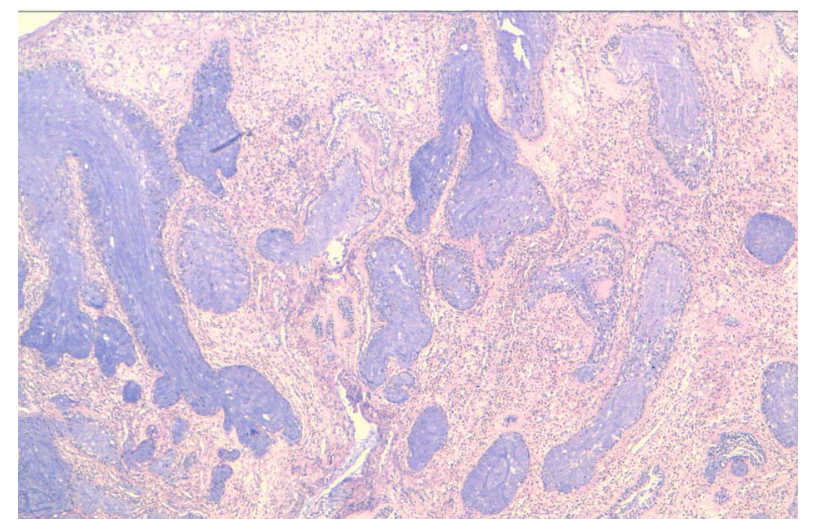

Figure 2. HES $\times 4$. Lobular adenomatous proliferations with tubular glands showing ciliated columnar epithelium.

of these 3 citations being single case reports [5,6]. The lesion goes unmentioned in most textbooks of general pathology, and its discussion in texts limited to head and neck pathology typically consists of less than a single page of text $[3,4,7]$. Therefore, it seems reasonable to presume that the REAH is a lesion that most pathologists may never have encountered. Involvement of the maxillary sinus by REAH is particularly rare. The original 31 cases reported by Wenig and Heffner1 did not include any lesions involving the maxillary sinus, and only one other report of a REAH involving the maxillary sinus was identified [5]. The etiology of the lesion is unclear and may be secondary to either sinonasal inflammation or developmental error. Though it is very rare, it is important to recognize this lesion because it can be confused histopathologically with other disease processes that would necessitate a significantly different treatment approach. The first differential diagnosis of REAH is the inflammatory polyp $[1,8,9]$. One of the most notable clinical differences between REAH and inflammatory polyps is the location, in that the bulk of REAHs involve the posterior nasal septum $[1,8,10]$. Both lesions can show fibroblastic and vascular proliferation, stromal edema, a mixed inflammatory cell infiltrate, and seromucinous gland proliferation $[1,10]$. However, inflammatory polyps do not have florid adenomatoid proliferation and stromal hyalinization which, when present, favor REAH. Inverted papillomas, or the inverted type of Schneiderian papillomas, are the second differential in the diagnosis of REAH. Inverted papillomas are considered true neoplasms and require more extensive surgical excision to remove the tumor and possible dysplastic foci $[8,10]$. The inverted papilloma growth of squamous epithelium is not seen in REAH. Occasional mitoses may be seen in the basal layer, and there is usually mild to moderate atypia [11]. Sinonasal adenocarcinoma is the third differential diagnosis for REAH. It accounts for approximately $20 \%$ of all sinonasal malignancies and is classified into salivary and non salivary types $[10,11]$. Adenocarcinomas without a specific salivary gland tumor pattern usually arise on the middle turbinate or in the ethmoid sinus; from there it extends laterally into the orbit and upward into the anterior cranial fossa [11].

On microscopic examination, sinonasal adenocarcinomas show a wide range of differentiation and patterns. Intestinal type adenocarcinomas are of high grade. The most common architecture is the tubulopapillary type but goblet cell, signet ring, and mucinous types have been described $[10,11]$. Differentiating the intestinal type sinonasal adenocarcinoma from REAH is usually not difficult as the cell types, high grade features, and greatly increased mitoses are features of adenocarcinoma [10]. Furthermore, REAH does not show the features of adenocarcinoma including nuclear stratification, dysplasia, and increased mitotic rate [11].

Respiratory epithelial adenomatoid hamartoma truly is a lesion in its infancy. Described only a decade ago, it is an uncommon entity with distinctive morphologic features. Clinically, it is an expansive mass which causes upper respiratory symptoms and discomfort mainly in adult men, although cases in women and children have been reported. Distinctive histologic features include a glandular component which originates from the overlying surface respiratory epithelium and polypoid growth as a result of respiratory epithelial adenomatoid proliferation. The columnar cells lining the glands are ciliated, further illustrating the benign nature of the lesion. Diagnostic misinterpretation is a serious issue regarding this lesion. Pathologists must be aware of this entity in order to avoid overdiagnosis and excessive surgical procedures for the patient. 


\section{REFERENCES}

[1] B. M. Wenig and D. K. Heffner, "Respiratory Epithelial Adenomatoid Hamartomas of the Sinonasal Tract and Nasopharynx: A Clinicopathologic Study of 31 Cases,” Annals of Otology, Rhinology and Laryngology, Vol. 104, No. 8, 1995, pp. 639-645.

[2] L. Barnes, "Schneiderian Papillomas and Nonsalivary Glandular Neoplasms of the Head and Neck," Modern Pathology, Vol. 15, No. 3, 2002, pp. 279-297. doi:10.1038/modpathol.3880524

[3] B. Perez-Ordonez and A. G. Huvos, "Respiratory Epithelial Adenomatoid Hamartoma,” In: D. R. Gnepp, Ed., Diagnostic Surgical Pathology of the Head and Neck, W. B. Saunders Company, Philadelphia, 2001, p. 91.

[4] L. Barnes, "Respiratory Epithelial Adenomatoid Hamartoma,” In: L. Barnes, Ed., Surgical Pathology of the Head and Neck, 2nd Edition, Marcel Dekker, Inc., New York, 2001, pp. 485-486.

[5] Y. Himi, T. Yoshizaki, K. Sato and M. Furukawa, "Respiratory Epithelial Adenomatoid Hamartoma of the Maxillary Sinus," Journal of Laryngology \& Otology, Vol. 116, No. 4, 2002, pp. 317-318. doi:10.1258/0022215021910672

[6] R. Endo, H. Matsuda, M. Takahashi, M. Hara, H. Inaba and M. Tsukuda, "Respiratory Epithelial Adenomatoid Hamartoma in the Nasal Cavity,” Acta Otolaryngology, Vol. 122, No. 4, 2002, pp. 398-400.

\section{doi:10.1080/00016480260000085}

[7] S. E. Mills, M. J. Gaffey and H. F. Frierson Jr., "Tumors of the Upper Aerodigestive Tract and Ear,” In: J. Rosai and L. H. Sobin, Eds., Atlas of Tumor Pathology, 3rd Series, Fascicle 26, Armed Forces Institute of Pathology, Washington DC, 2000, pp. 357-359.

[8] C. Delbrouck, S. F. Aguilar, G. Choufani and S. Hassid, "Respiratory Epithelial Adenomatoid Hamartoma Associated with Nasal Polyposis," American Journal of Otolaryngology, Vol. 25, No. 4, 2004, pp. 282-284. doi:10.1016/j.amjoto.2004.02.005

[9] H. P. Kessler and B. Unterman, "Respiratory Epithelial Adenomatoid Hamartoma of the Maxillary Sinus Presenting as a Periapical Radiolucency: A Case Report and Review of the Literature," Oral Surgery, Oral Medicine, Oral Pathology, Oral Radiology and Endodontology, Vol. 97, No. 5, 2004, pp. 607-612. doi:10.1016/j.tripleo.2003.09.013

[10] A. R. Sangoi and G. Berry, "Respiratory Epithelial Adenomatoid Hamartoma: Diagnostic Pitfalls with Emphasis on Differential Diagnosis," Advances in Anatomic Pathology, Vol. 14, No. 1, 2007, pp. 11-16. doi:10.1097/PAP.0b013e31802efb1e

[11] J. Rosai, “Respiratory Tract,” In: J. Rosai, Ed., Rosai and Ackerman's Surgical Pathology, 9th Edition, Elsevier, Inc., New York, 2004, pp. 308-311. 